\title{
REDECA
}

CI ÊNCIAS CONTÁBEIS

ATUÁRIA E MÉTODOS QUANTITATIVOS

\section{RELAÇÃO ENTRE INCENTIVOS FISCAIS E INDICADORES ECONÔMICO- FINANCEIROS DE EMPRESAS ABERTAS BRASILEIRAS}

\author{
Henrique Formigoni ${ }^{1}$ \\ Liliane Cristina Segura ${ }^{2}$ \\ Daniella Gomes Alves Teixeira ${ }^{3}$ \\ Daniel Cardamone Carvalho ${ }^{4}$ \\ Mateus Guazzelli Marotti ${ }^{5}$
}

\begin{abstract}
RESUMO
Este artigo tem como objetivo analisar a relação entre incentivos fiscais e indicadores econômico-financeiros de empresas abertas brasileiras não financeiras. A pesquisa é do tipo descritiva, com abordagem quantitativa; a população são as companhias abertas brasileiras, não financeiras, listadas na B3 - Brasil, Bolsa e Balcão e a amostra final foi composta por 450 empresas. Os dados foram coletados através das demonstrações financeiras das empresas, disponíveis no banco de dados da Economática e tratados no Statistical Package for the Social Sciences - SPSS. Realizou-se o teste U de Man Whitney, em virtude de que a amostra não apresentou distribuição normal. Os indicadores considerados foram aqueles utilizados na literatura e que proporcionaram a análise da rentabilidade e dos impactos econômicofinanceiros das empresas. O principal resultado indica que companhias abertas brasileiras não financeiras que usufruem de incentivos ficais apresentam uma situação econômico-financeira mais favorável do que empresas que não usufruem de tais incentivos. A conclusão do estudo é que incentivos fiscais e indicadores econômico-financeiros de empresas brasileiras não financeiros têm forte relação.
\end{abstract}

Palavras-chave: Incentivos Fiscais, Indicadores Econômico-financeiros, Empresas Brasileiras.

\footnotetext{
${ }^{1}$ Universidade Presbiteriana Mackenzie.

${ }^{2}$ Universidade Presbiteriana Mackenzie.

${ }^{3}$ Universidade Presbiteriana Mackenzie.

${ }^{4}$ Universidade Presbiteriana Mackenzie.

${ }^{5}$ Universidade Presbiteriana Mackenzie.
} 


\title{
REDECA
}

\section{CI ÊNCIAS CONTÁBEIS}

\begin{abstract}
On this undergraduate thesis, we have a research objective, which is to analyze the link between tax incentives and economic-financial indicators of publicly traded companies. The research is descriptive with quantitative approach. The target public are Brazilian non-financial listed companies. The data will be collected from financial statements of companies, which is available in the database Economática. The data processing will be done by test $U$ the Man Whitney. The indicators to be considered are those that provide the analysis of the profitability and economic-financial impacts of the tax incentives in the financial statements of Brazil companies. The main result indicates that Brazilian non-financial companies that enjoy tax incentives have a more favorable economic-financial situation than companies that do not benefit from such incentives. The conclusion of the study is that fiscal incentives and economicfinancial indicators of Brazilian non-financial companies have a strong relationship.
\end{abstract}

Keywords: Tax breaks, financial, economic indicators and Brazilian companies. 
Formigoni, H., Segura, L. C., Teixeira, D. G. A., Carvalho, D. C., Marotti, M. G.; Relação entre incentivos fiscais e indicadores econômicos-financeiros de empresas abertas brasileiras.

\section{INTRODUÇÃO}

No Brasil, os incentivos fiscais estão diretamente relacionados aos tributos, para investir e custear as atividades públicas constitucionais, sempre visando favorecer a população. Segundo o Tribunal de Contas da União - TCU (2017), carga tributária caracteriza-se como a parcela dos tributos arrecadados dos contribuintes pelo Estado, cuja finalidade destina-se ao financiamento das ações do governo em benefício da população e de forma a atender o plano de governo.

Para se ter uma ideia do peso da carga tributária brasileira na competitividade, segundo o relatório do World Economic Forum (WEF, 2016) o Brasil tem a sétima maior carga tributária dentre os 25 países com maiores cargas tributárias do mundo, com base em dados como níveis de corrupção, inflação e estabilidade política. Embora tenha essa alta carga tributária, em termos de competitividade o Brasil se encontra na $72^{\mathrm{a}}$ posição no ranking global de competitividade, dentre os 140 países considerados no estudo (WEF, 2018). Ainda, no ranking de retorno oferecido em qualidade de vida e serviços públicos para a população, considerando as esferas federal, estadual e municipal, elaborado pelo Instituto Brasileiro de Planejamento Tributário (IBPT, 2018), em sua oitava edição, o Brasil continua classificado em último lugar.

Dentre os outros países que possuem carga tributária elevada, vários têm elevado produto interno bruto (PIB) per capita e Índice de Desenvolvimento Humano (IDH), por isso são considerados mais desenvolvidos, fornecendo melhor retorno dos tributos cobrados, comparativamente ao Brasil (IBPT, 2018).

Segundo dados da Secretaria da Receita Federal do Brasil - SRFB (BRASIL, 2017a), em 2015 a carga tributária aumentou 0,24 pontos percentuais, comparativamente ao ano anterior, 2014, apesar do PIB ter sofrido redução no mesmo período. Esse aumento da carga tributária ocorreu devido aos parcelamentos de impostos concedidos em anos anteriores, fato responsável pelo aumento contínuo do percentual da carga tributária arrecadada anualmente, comparado a períodos anteriores. A Figura 1 apresenta a evolução da carga tributária no Brasil de 2006 a 2015. 
Formigoni, H., Segura, L. C., Teixeira, D. G. A., Carvalho, D. C., Marotti, M. G.; Relação entre incentivos fiscais e indicadores econômicos-financeiros de empresas abertas brasileiras.

Figura 1 - Evolução da carga tributária no Brasil de 2006 a 2015, com e sem arrecadação de parcelamentos de tributos:

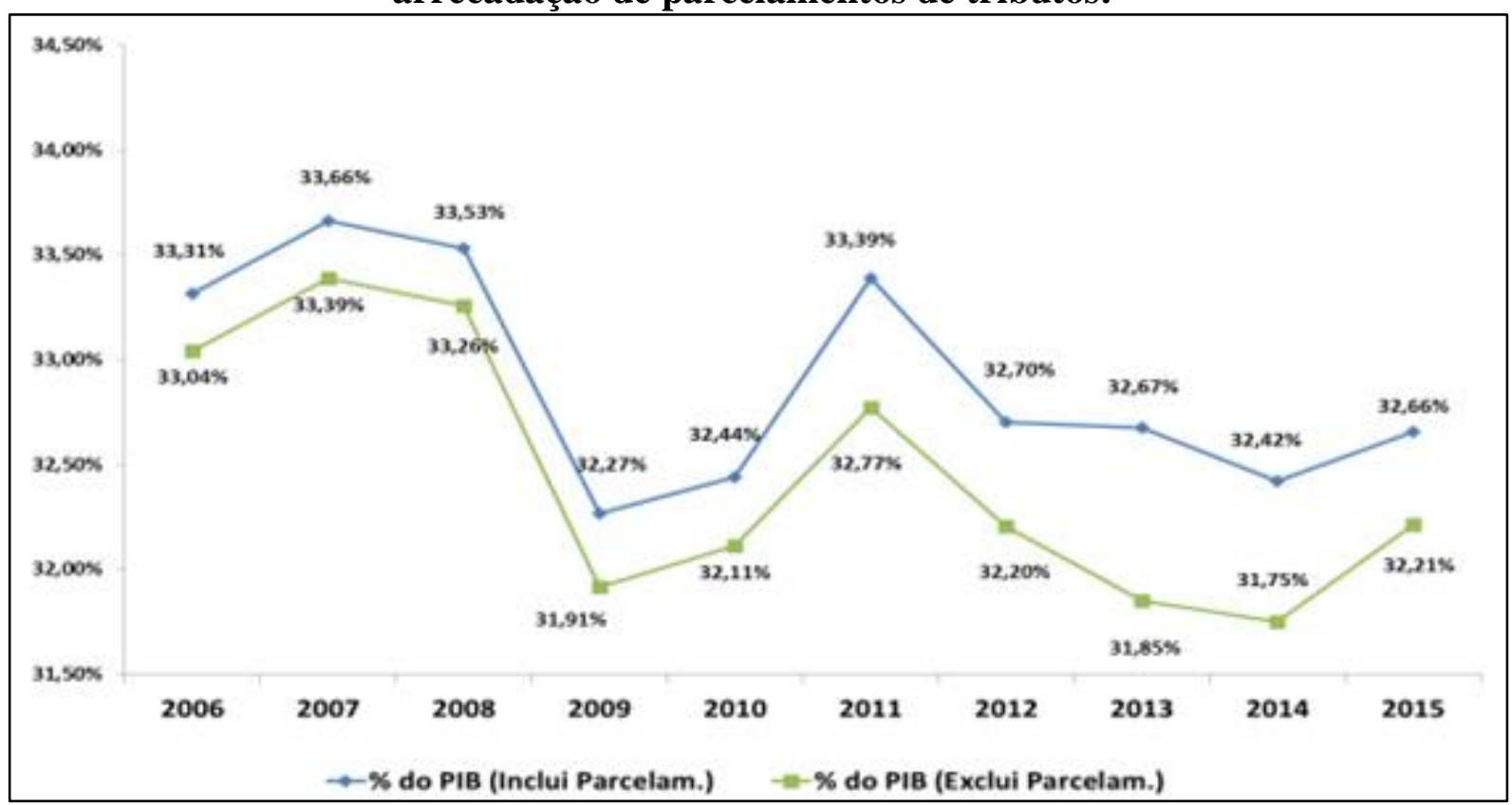

Fonte: Receita Federal do Brasil - SRFB, 2017.

Segundo o Ministério da Fazenda (BRASIL, 2016, p. 3), “(...) a desigualdade nos estratos mais altos da sociedade é elevado e vem aumentando", resultado da má distribuição de renda. Este fato afeta o índice de desenvolvimento econômico do Brasil em perspectiva global, de forma negativa, ao fato que países desenvolvidos se destacam por ter um padrão moderado de desigualdade social e impacto positivo nas atividades empresariais.

Para minimizar os efeitos tributários na competitividade das empresas o governo introduziu no Brasil, em 1990, os incentivos fiscais, que têm como principal objetivo o aumento da efetividade de empresas brasileiras que utilizam o benefício deste instrumento financeiro, que concilia os interesses do setor privado no aumento da competitividade de mercado, com os interesses dos estados em desenvolver suas regiões, segundo o Ministério da Integração Nacional (BRASIL, 2017b).

O Ministério da Integração Nacional (BRASIL, 2017b) apresenta os incentivos fiscais como instrumentos da Política Nacional de Desenvolvimento Regional (PNDR), que visam estimular o desenvolvimento social e econômico nas regiões, propondo uma melhor distribuição de renda ou ampliação de renda da população local, inclusive associado ao desenvolvimento econômico regional. 
Formigoni, H., Segura, L. C., Teixeira, D. G. A., Carvalho, D. C., Marotti, M. G.; Relação entre incentivos fiscais e indicadores econômicos-financeiros de empresas abertas brasileiras.

Os benefícios associados aos incentivos fiscais apresentam diferentes interpretações quanto aos beneficiários de seus resultados. Segundo Kannebley Junior e Porto (2012), incentivos ficais são instrumentos financeiros eficazes em relação ao desenvolvimento da renda de toda a população regional. Contudo, para que isso ocorra, o governo faz a renúncia fiscal sobre o direito de receber imposto de uma empresa específica, em uma região específica, e esta empresa recebe os benefícios fiscais acordados. Os instrumentos financeiros, na forma de incentivos fiscais do IR, têm como objetivo, aumentar a renda regional, o instrumento visa beneficiar a população e não os empresários.

Conforme apontado por Gadelha (2010, p. 98), os “(...) incentivos fiscais são medidas que estimulam a realização de determinada conduta", portanto, pode ser enquadrado como um instrumento de intervenção no domínio econômico e tem a função de gerar valor econômico. Incentivo fiscal está interligado ao desenvolvimento econômico de uma determinada região ou um determinado setor de atividade. Calderaro (1973, p.17) também discorre sobre os benefícios dos incentivos fiscais e destaca que estes decorrem de normas que excluem total ou parcialmente o crédito tributário, com a finalidade de estimular o desenvolvimento econômico de determinado setor de atividade ou região do país.

Nota-se que os incentivos fiscais estão totalmente vinculados a benefícios econômicofinanceiros, pois todo incentivo está vinculado à um benefício financeiro favorável para as empresas, seja por uma suspensão, extinção ou exclusão da obrigação tributária. Isso impacta a estrutura econômico-financeira da empresa e os seus indicadores econômico-financeiros, que evidenciam quais são os impactos e efeitos desses benefícios nas companhias (SILVIA, 2005, p. 248).

Sendo assim, dada que a principal função dos indicadores econômico-financeiros é demonstrar a situação econômico-financeira de uma companhia, através da relação entre as contas contábeis, tem-se que os efeitos proporcionados por incentivos fiscais, por serem totalmente vinculados a benefícios financeiros, podem afetar os indicadores que evidenciam o nível de liquidez, rentabilidade, atividade e lucratividade.

Tendo em vista o cenário apresentado, este estudo toma como base o seguinte problema de pesquisa: Qual é a relação entre incentivos fiscais e os indicadores econômico-financeiros de companhias abertas brasileiras não financeiras? Em vista dessa questão de pesquisa, o 
Formigoni, H., Segura, L. C., Teixeira, D. G. A., Carvalho, D. C., Marotti, M. G.; Relação entre incentivos fiscais e indicadores econômicos-financeiros de empresas abertas brasileiras.

objetivo deste artigo é analisar a relação entre incentivos fiscais e os indicadores econômicofinanceiros de companhias abertas brasileiras não financeiras.

A relevância do tema, incentivos fiscais, é destacada nos relatórios de planejamento da Lei Orçamentaria Anual e na Lei de Diretrizes Orçamentárias, Lei Complementar $n^{\circ} 101$, de 4 de maio de 2000 (BRASIL, 2000), que são instrumentos de planejamento tático e operacional, formulados anualmente, e que devem apresentar todos os benefícios concedidos para cada nível de governo e suas formas de compensação, sendo que, anualmente, são renunciados bilhões de reais no Brasil via incentivos fiscais (TCU, 2017). Segundo Rodrigues e Rodrigues (2017), de acordo com projeção da Receita Federal, as políticas de incentivos fiscais custarão ao governo R\$ 283,4 bilhões em 2018. O Projeto de Lei Orçamentária Anual - PLOA prevê renúncias de receitas para 2019 no montante de $\mathrm{R} \$ 306$ bilhões (BRASIL, 2019).

Segundo o relatório do Tribunal de Contas da União - TCU (2017), os incentivos fiscais impactam de forma relevante o orçamento dos Estados, como demonstrado no Gráfico 1, que apresenta o valor das obrigações tributárias renunciado pelos Estados em função dos incentivos fiscais no período de 2014 a 2018.

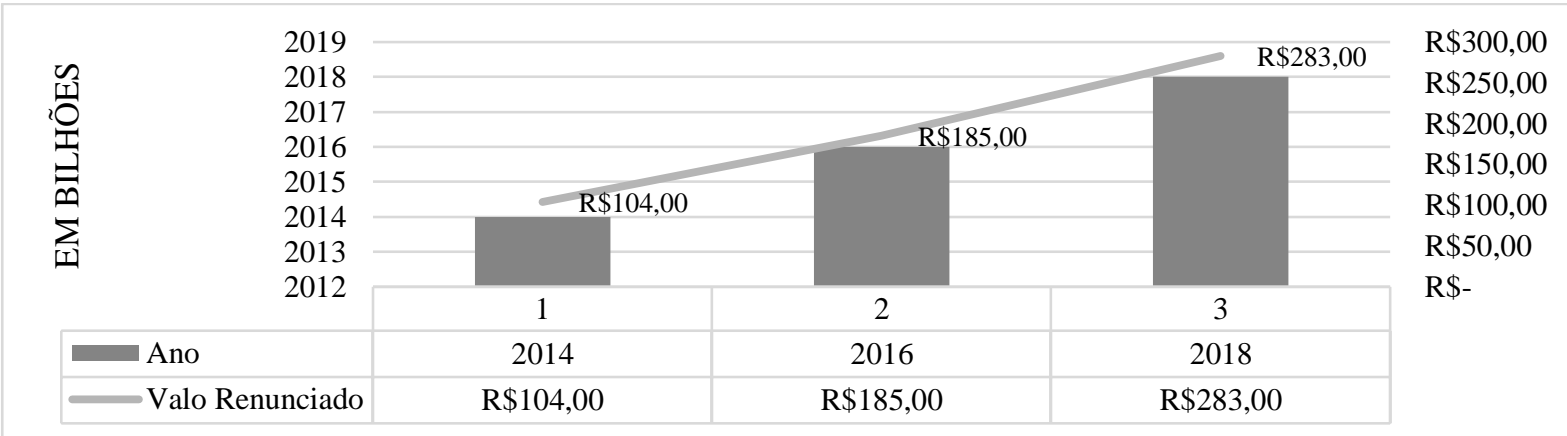

Gráfico 1 - Valor das obrigações tributárias renunciadas em função dos incentivos fiscais. Fonte: TCU, 2017.

O Gráfico 1 demonstra que o valor das obrigações tributárias renunciadas em função dos incentivos fiscais vem se elevando cada vez mais, demonstrando tanto a relevância quanto a atualidade do tema tratado, com impactos econômico-financeiros e sociais.

Portanto, este estudo contribui para o aprimoramento da discussão acadêmica de gestão e planejamento tributário voltados a incentivos fiscais, melhorando a percepção da relação entre os incentivos fiscais e os indicadores econômico-financeiros de empresas brasileiras. 
Formigoni, H., Segura, L. C., Teixeira, D. G. A., Carvalho, D. C., Marotti, M. G.; Relação entre incentivos fiscais e indicadores econômicos-financeiros de empresas abertas brasileiras.

Por fim, contribui empiricamente com a comunidade empresarial, verificando a rentabilidade de empresas que possuem incentivos fiscais comparativamente àquelas que não possuem; e, com o planejamento governamental, identificando a relação entre os indicadores econômico-financeiros das empresas que usufruem ou não dos incentivos fiscais.

\section{REFERENCIAL TEÓRICO}

\subsection{Incentivos Fiscais}

O Ministério da Integração Nacional (BRASIL, 2017b), define como incentivo fiscal o ato de renúncia de receita pública em benefício do contribuinte e acrescenta que esses são instrumentos da Política Nacional de Desenvolvimento Regional (PNDR). Sendo que a PNDR visa estimular a formação de capital fixo nas regiões, definidas no acordo firmado entre o estado e os autônomos, com o objetivo de alavancar o desenvolvimento econômico e social, sempre respeitando a restrição orçamentária e temporal determinada.

Incentivos fiscais também são definidos como instrumentos baseados em desoneração tributária, com tratamento diferenciado, com o objetivo de: promover o desenvolvimento econômico regional, fomentando determinados setores produtivos ou regiões; reduzir as desigualdades sociais nacionais e regionais; aumentar o saldo da balança comercial; colocar os produtos de fabricação nacional no mercado externo; desenvolver o parque industrial nacional e gerar empregos (FORMIGONI, 2008; MELO, 2007).

Os incentivos fiscais não visam privilegiar o ente contribuinte, mas, promover ações e comportamentos de fomento econômico em prol da sociedade. Sendo assim, incentivos fiscais possuem caráter extrafiscal, pois têm grande influência sobre as ações da população local e não são caracterizados obrigatoriamente como obrigação tributária e sim como um acordo entre os estados e empresas que possibilitam o aquecimento da economia local, sempre com o intuito de desenvolvimento regional (RIBEIRO, 2009).

Contemplam o gênero de incentivos fiscais: as isenções, redução de alíquota que incide na base de cálculo, alíquota zero, subvenções, créditos presumidos, subsídio e diferimento (FORMIGONI, 2008). Essa aparente pluralidade gera, por vezes, dificuldades quanto a sua aplicação e utilização, inclusive em discussões acadêmicas. 
Formigoni, H., Segura, L. C., Teixeira, D. G. A., Carvalho, D. C., Marotti, M. G.; Relação entre incentivos fiscais e indicadores econômicos-financeiros de empresas abertas brasileiras.

O Quadro 1 identifica as principais leis instituidoras de incentivos fiscais, detalhadas quanto a sua competência governamental, quanto ao tributo a que a lei se refere, o público alvo beneficiário direto ou área de atuação, os limites percentuais de destinação de imposto para pessoa jurídica e a dedução máxima que a empresa pode efetuar.

Quadro 1 - Principais leis instituidoras dos incentivos fiscais

\begin{tabular}{|c|c|c|c|c|c|}
\hline Lei & Competência & Trib. & $\begin{array}{l}\text { Público ou área } \\
\text { de atuação }\end{array}$ & $\begin{array}{l}\text { Limite de } \\
\text { destinação }\end{array}$ & $\begin{array}{l}\text { Dedução máxima do } \\
\text { limite de destinação }\end{array}$ \\
\hline Fumcad & Municipal & IR & $\begin{array}{c}\text { Criança e } \\
\text { adolescente; } \\
\text { educação e saúde }\end{array}$ & $1 \%$ & $100 \%$ \\
\hline $\begin{array}{l}\text { Fundo Nacional } \\
\text { do idoso }\end{array}$ & Federal & IR & Idoso; saúde & $1 \%$ & $100 \%$ \\
\hline $\begin{array}{l}\text { Lei do } \\
\text { Audiovisual }\end{array}$ & Federal & IR & Cultura & $3 \%$ & $\begin{array}{c}100 \% \text { pelo artigo } 18 \mathrm{CF} ; \\
\text { ou } 40 \% \text { do valor da doação } \\
\text { e } 30 \% \text { do valor em } \\
\text { patrocínio pelo artigo } 26 \\
\text { CF }\end{array}$ \\
\hline Lei Rouanet & Federal & IR & Cultura & $4 \%$ & $100 \%$ \\
\hline $\begin{array}{l}\text { Lei Federal de } \\
\text { incentivos ao } \\
\text { esporte }\end{array}$ & Federal & IR & Esporte & $1 \%$ & $70 \%$ \\
\hline Lei Mendonça & $\begin{array}{l}\text { Municipal } \\
\text { (SP) }\end{array}$ & $\begin{array}{c}\text { ISS } \\
\text { IPTU }\end{array}$ & Cultura & $20 \%$ & $100 \%$ \\
\hline $\begin{array}{l}\text { Lei Paulista de } \\
\text { Incentivo ao } \\
\text { esporte }\end{array}$ & Estadual (SP) & ICMS & Esporte & $3 \%$ & $100 \%$ \\
\hline $\begin{array}{l}\text { Programa da } \\
\text { ação cultural }\end{array}$ & Estadual (SP) & ICMS & Cultura & $3 \%$ & $100 \%$ \\
\hline Pronas/PCD & Federal & IR & Saúde & $1 \%$ & $100 \%$ \\
\hline Pronon. & Federal & IR & Saúde & $1 \%$ & $100 \%$ \\
\hline Vale-Cultura & Federal & IR & $\begin{array}{l}\text { Funcionário; } \\
\text { cultura }\end{array}$ & $1 \%$ & $100 \%$ \\
\hline
\end{tabular}

Fonte: Steagall, Loo e Brito, 2015.

O Quadro 1 evidencia que as principais leis instituidoras de incentivos fiscais têm competência Federal (União) e o tributo com maior influência de dedução é o Imposto de renda (IR).

Os incentivos fiscais são benefícios que geram isenção total ou parcial das obrigações tributárias, para empresas privadas, com a condição de desenvolver a renda da população local além da empresa ter de se instalar na região (Estados) que oferece o benefício (PUREZA, 2017).

O Comitê de Pronunciamentos Contábeis (2010), por meio do pronunciamento técnico CPC 07 - R1, que trata de subvenções e assistências do governo, esclarece que os benefícios econômicos concedidos às empresas devem ser reconhecidos no momento em que for seguro 
Formigoni, H., Segura, L. C., Teixeira, D. G. A., Carvalho, D. C., Marotti, M. G.; Relação entre incentivos fiscais e indicadores econômicos-financeiros de empresas abertas brasileiras.

afirmar que a entidade cumprirá todas as condições estabelecidas e a subvenção será recebida. O simples recebimento das subvenções não é prova conclusiva de que as condições a ela vinculadas, tenham sido ou serão cumpridas.

2.1.1. Disfunção econômica de mercado e Guerra Fiscal.

O conceito de guerra fiscal está associado a ação de alguns Estados brasileiros que utilizam os incentivos fiscais como uma ferramenta política e econômica. Os entes federativos têm o poder de decisão discricionário sobre a destinação dos benefícios fiscais, assim utilizam estes como um mecanismo de atração de novas empresas para seus territórios com o objetivo de gerar mais empregos para a população local e, por vezes, de autopromoção política.

Além da disfunção econômica de mercado, o fato dos Estados terem o poder de destinar o benefício dos incentivos fiscais para a entidade ou setor econômico que avaliar digno de desenvolvimento, impacta, consequentemente, os recursos tributários do Estado de origem dessas "novas empresas", pois este é prejudicado pela saída dessas, ou seja, para um Estado ganhar outro Estado perde. Segundo Alves (2017) os incentivos fiscais são benéficos para as empresas privadas que usufruem do benefício e para o Estado que atrai a empresa, mas todos os outros Estados são prejudicados. Ele destaca que o recurso arrecadado pelo Estado concedente dos incentivos fiscais diminui, em virtude da renúncia de receitas tributárias, o que faz com que a União inteire as necessidades econômicas dos Estados via repasses e transferências.

Em suma, as guerras fiscais são movidas pelos interesses políticos internos de cada Estado na busca de arrecadação fiscal individual dos tributos cobrados de empresas privadas. Esta arrecadação é importante para que o Estado tenha recursos para o suporte aos serviços públicos prestados à população, pois caso tenha falta de recursos, o impacto econômicofinanceiro recai diretamente nos serviços prestados pelo Estado. Para que essa competição por arrecadação tributária se encerre, é necessária uma intervenção política, que crie uma reforma tributária sólida (ALVES, 2017). 
Formigoni, H., Segura, L. C., Teixeira, D. G. A., Carvalho, D. C., Marotti, M. G.; Relação entre incentivos fiscais e indicadores econômicos-financeiros de empresas abertas brasileiras.

\subsubsection{Regime jurídico, finalidade e formas de Incentivos Fiscais}

Quanto à finalidade, os incentivos fiscais, podem ser classificados em três espécies: incentivo fiscal global ou geral, incentivo fiscal regional e incentivo fiscal setorial. Os incentivos gerais ou globais, são aqueles concedidos a empresas para promover o desenvolvimento industrial de um determinado setor de atividade (PORTINHO, 2002); os incentivos fiscais regionais visam atender os interesses gerais da população local (FORMIGONI, 2008); e os incentivos fiscais setoriais têm por objetivo incentivar economicamente o desenvolvimento especifico da região que oferece os benefícios dos incentivos fiscais (ELALI, 2007).

Formigoni (2008) explica que na literatura não existe uniformidade em relação a definição dos termos imunidade, isenção e não-incidência. Esses institutos e instrumentos jurídicos são interpretados como se fossem o mesmo, porém, pode-se observar no Quadro 2 que existem diferenças conceituais entre isenção, imunidade e não incidência. De forma geral, embora haja definição para cada um dos termos, não é fácil o seu entendimento e distinção para quem não é da área jurídica.

Deve-se entender que instituto jurídico é a norma jurídica que rege um tipo de relação social ou interesse e que se identifica pelo fim que procura realizar, como, por exemplo, o casamento, a falência, entre outras situações totalmente relacionadas ao convívio social (MAZZILLI, 2012).

Os instrumentos jurídicos são utilizados para embasar a atribuição dos benefícios físcais e seus resultados, para estabelecer a forma e condições a serem atendidas pelas empresas que têm interesse de gozar dos benefícios (MAZZILLI, 2012). A OAB - Ordem dos Advogados do Brasil (2018) explica que é grande a dificuldade para o entendimento da diferença entre isenção e imunidade e que mesmo aqueles que usufruem das isenções e imunidades tributárias, confundem a definição e finalidade dos conceitos. O Quadro 2 evidencia a diferença conceitual dos termos. 
Formigoni, H., Segura, L. C., Teixeira, D. G. A., Carvalho, D. C., Marotti, M. G.; Relação entre incentivos fiscais e indicadores econômicos-financeiros de empresas abertas brasileiras.

Quadro 2 - Isenção, imunidade e não incidência.

\begin{tabular}{|c|l|}
\hline Conceito & \multicolumn{1}{c|}{ Definição } \\
\hline Isenção & $\begin{array}{l}\text { Benefício fiscal que gera a desoneração do pagamento de tributo que é instituído por lei. } \\
\text { A isenção é um instrumento de política fiscal utilizado pelo governo para incentivar } \\
\text { determinados segmentos econômicos. }\end{array}$ \\
\hline Imunidade & $\begin{array}{l}\text { "A qualidade da situação que não pode ser atingida pelo tributo, em razão de normas } \\
\text { constitucionais que, à vista de alguma especificidade pessoal ou material dessa situação, } \\
\text { deixou-a fora do campo sobre o qual é autorizada a imunidade, isenção ou não incidência } \\
\text { do tributo", }\end{array}$ \\
\hline Não incidência & $\begin{array}{l}\text { A não incidência decorre da noção de hipótese de incidência (descrição normativa do fato } \\
\text { gerador do tributo) que através da ocorrência de um fato, gera a obrigação tributária, } \\
\text { diferente do fato gerador, que é a concretização da hipótese de incidência. }\end{array}$ \\
\hline
\end{tabular}

Fonte: Manual de Direito Tributário, 2014.

2.1.3. Reconhecer, mensurar e evidenciar os incentivos fiscais

O reconhecimento, mensuração e evidênciação (divulgação) dos incentivos fiscais compõem o processo de elaboração e evidenciação contábil, sendo que, na fase do reconhecimento dos eventos econômicos, o incentivo fiscal só deve ser reconhecido se for provável que os benefícios econômicos futuros fluirão para a entidade e se os custos ou valores puderem ser mensurados de forma confiável (NIYAMA et al. 2012). Assim, só será efetuado o reconhecimento, nas demonstrações contábeis, se os elementos patrimoniais atenderem aos critérios de reconhecimento de ativos, passivos, receitas e despesas.

Quanto à mensuração dos incentivos fiscais, pode ser feita por valores de entrada ou de saída, mas a regra geral das normas contábeis é a de mensurar incentivos fiscais pelo valor de entrada e, prioritariamente, pelo custo histórico, de modo geral. Segundo Niyama et al. (2012), o foco da mensuração é mostrar a realidade econômica dos objetos e eventos.

Uma vez reconhecido, os dados dos incentivos fiscais devem ser evidenciados conforme o Pronunciamento Técnico CPC 07 (R1), que determina a divulgação das seguintes informações: (i) política contábil adotada para as subvenções governamentais, incluindo os métodos de apresentação adotados nas demonstrações contábeis; (ii) natureza e extensão das subvenções governamentais ou assistências governamentais reconhecidas nas demonstrações contábeis e uma indicação de outras formas de assistência governamental de que a entidade tenha diretamente se beneficiado; (iii) condições a serem regularmente satisfeitas e outras contingências ligadas à assistência governamental que tenha sido reconhecida. 
Formigoni, H., Segura, L. C., Teixeira, D. G. A., Carvalho, D. C., Marotti, M. G.; Relação entre incentivos fiscais e indicadores econômicos-financeiros de empresas abertas brasileiras.

\subsection{INDICADORES ECONÔMICOS-FINANCEIROS}

Indicadores econômico-financeiros são definidos por Silva (2005, p. 248) como "relações entre contas ou grupos de contas das demonstrações contábeis, que têm por objetivo fornecer-nos informações que não são visíveis ao analisar as demonstrações de forma direta"'.

Estes indicadores são uma das ferramentas utilizadas pelas empresas para analisar a sua situação econômico-financeira através de uma interpretação avançada. Este método possibilita que seja identificado o fator responsável por ganhos ou perdas das empresas no período analisado (Rameiro, Coelho, 2011).

O objetivo dos indicadores é verificar se a administração junto com a governança atingiu todos os objetivos financeiros que a companhia pré-estabeleceu no início do exercício. Através desta avaliação, feita pelos indicadores, a administração junto à governança, poderá mensurar o resultado econômico-financeiro da companhia (CATELLI, 2001).

As informações contábeis são direcionadas de duas formas, a primeira é voltada aos interesses dos usuários internos, tais como gerentes e diretores, e a segunda voltada aos interesses dos usuários externos, tais como fornecedores, e acionistas. Segundo Ching (2006), a contabilidade gerencial direciona as informações aos usuários internos e a contabilidade financeira aos usuários externos. Cumprindo os requisitos da Lei n ${ }^{\circ}$ 6.404/1976 - Legislação das Sociedades Anônimas (BRASIL, 1976), a contabilidade financeira evidencia o histórico e a situação econômico-financeira atual da entidade e impacta diretamente na tomada de decisão do usuário externo.

Os indicadores econômico-financeiros são utilizados para analisar uma entidade de forma individual, mas também podem ser utilizados para analisar um grupo de empresas, associado a um objeto de análise, como o que se pretende realizar neste estudo: empresas brasileiras de capital aberto que possuem ou não incentivos fiscais.

Para que esta análise ocorra de forma satisfatória é necessário que os indicadores sejam calculados para cada empresa e, depois, analisados e comparados em grupo. 
Formigoni, H., Segura, L. C., Teixeira, D. G. A., Carvalho, D. C., Marotti, M. G.; Relação entre incentivos fiscais e indicadores econômicos-financeiros de empresas abertas brasileiras.

Um dos modelos de análises possíveis de avaliação do desempenho empresarial é realizado por meio dos índices de processos. São índices que evidenciam o real resultado econômico-financeiro dos processos aplicados pela companhia, apresentando a sua evolução econômico-financeira através dos indicadores de: liquidez, rentabilidade, atividade, lucratividade e de estrutura de capital. Conforme Ferreira e Callado (2017), estes indicadores são utilizados para planejar, controlar e avaliar as operações e a situação econômico-financeira das entidades.O Quadro 3 apresenta uma síntese dos indicadores de processos.

Quadro 3 - Indicadores de Processos.

\begin{tabular}{|c|c|}
\hline Índices & Definição \\
\hline Liquidez & $\begin{array}{c}\text { Analisa quão eficiente a empresa é para liquidar seus passivos de curto e longo prazo. } \\
\text { Indicadores utilizados: liquidez seca, liquidez imediata, liquidez corrente e liquidez geral. }\end{array}$ \\
\hline Rentabilidade & $\begin{array}{c}\text { Indica a capacidade de retorno econômico-financeiro da empresa analisada e a maneira que } \\
\text { este lucro é consolidado e demonstra as evidências econômico-financeiras da empresa. } \\
\text { Índices utilizados: ROE, ROI e ROA. }\end{array}$ \\
\hline Lucratividade & $\begin{array}{c}\text { Relaciona os lucros apresentados na demonstração de resultados da empresa com a receita } \\
\text { de venda; em outras palavras, mede a eficiência econômico-financeira dos processos da } \\
\text { empresa analisada. Índices utilizados: margem EBIT, margem bruta, margem líquida e } \\
\text { variação do lucro líquido. }\end{array}$ \\
\hline $\begin{array}{c}\text { Estrutura de } \\
\text { Capital }\end{array}$ & $\begin{array}{c}\text { Os indicadores de estrutura de capital concedem proporcionalidades entre o capital de } \\
\text { terceiros e o patrimônio líquido. Índice utilizado: Endividamento. }\end{array}$ \\
\hline
\end{tabular}

Fonte: Assaf Neto (2010).

Esses indicadores podem ser eficientes se forem utilizados da melhor forma com as informações disponíveis na empresa.

\section{PROCEDIMENTOS METODOLÓGICOS}

A pesquisa é do tipo descritiva, pois busca a coleta e exposição do conteúdo investigativo, por descrição dos métodos aplicados e dos resultados obtidos (SAMPIERI; COLLADO; LUCIO, 2006), com abordagem quantitativa. Tem natureza empírica, cujo objeto de análise são as companhias abertas brasileiras não financeiras, e lógica de pesquisa dedutiva. Os dados são secundários e foram coletados das contas do balanço e da demonstração de resultado das empresas, utilizando o banco de dados da Economática (2017), e das notas explicativas das demonstrações contábeis disponíveis no site da B3.

A população foi composta por companhias abertas brasileiras não financeiras, listadas pela B3. A amostra foi constituída por 28 empresas que usufruem de incentivos fiscais e 422 que não usufruem, na data de 31 de dezembro de 2016, perfazendo, assim, o total de 450 empresas. 
Formigoni, H., Segura, L. C., Teixeira, D. G. A., Carvalho, D. C., Marotti, M. G.; Relação entre incentivos fiscais e indicadores econômicos-financeiros de empresas abertas brasileiras.

O tratamento dos dados foi realizado pelo teste estatístico não paramétrico U de Mann Whitney de diferença entre médias, em virtude de a amostra não apresentar distribuição normal.

Após a coleta dos dados, foi elaborada uma tabela no Excel, detalhada por empresa, a partir da qual foram calculados os indicadores econômico-financeiros necessários, apresentados no Quadro 4. Esses indicadores foram inseridos no programa Statistical Package for the Social Sciences - SPSS, para realização do teste estatístico.

Quadro 4 - Indicadores utilizados neste estudo.

\begin{tabular}{|c|c|c|c|}
\hline $\mathbf{N}^{\circ}$ & Índices & Indicador & Formula \\
\hline \multirow{4}{*}{1} & \multirow{4}{*}{ Liquidez } & Liquidez seca & (Ativo circulante - estoques) / Passivo circulante \\
\hline & & Liquidez imediata & Caixa / Passivo Circulante \\
\hline & & Liquidez corrente & Ativo Circulante / Passivo Circulante \\
\hline & & Liquidez geral & $\begin{array}{l}\text { Ativo Circulante + Realizável a Longo Prazo / Passivo } \\
\text { Circulante + Passivo não Circulante }\end{array}$ \\
\hline \multirow{3}{*}{2} & \multirow{3}{*}{ Rentabilidade } & ROE & (Receita líquida/ Patrimônio líquido) *100 \\
\hline & & ROI & (Receita - Custo / Custo) $* 100$ \\
\hline & & ROA & (Lucro líquido/ Ativo Total) $* 100$ \\
\hline \multirow{4}{*}{3} & \multirow{4}{*}{ Lucratividade } & Margem EBIT & Lucro Bruto/ Receita Bruta \\
\hline & & Margem Bruta & Lucro Bruto / Receita Líquida \\
\hline & & Margem líquida & Lucro Líquido/ Receita Líquida \\
\hline & & $\begin{array}{l}\text { Variação do lucro } \\
\text { liquido }\end{array}$ & Lucro Líquido Atual - Lucro Líquido Anterior \\
\hline 4 & Estrutura & Endividamento & Capital de Terceiros / Patrimônio líquido \\
\hline
\end{tabular}

Fonte: Elaborado pelos autores.

As hipóteses de estudo consideradas foram as seguintes:

H1 - As empresas com incentivos fiscais têm indicadores de liquidez maiores do que aquelas sem incentivos fiscais.

H2 - As empresas com incentivos fiscais têm indicadores de rentabilidade maiores do que aquelas sem incentivos fiscais.

H3 - As empresas com incentivos fiscais têm indicadores de lucratividade maiores do que aquelas sem incentivos fiscais.

H4 - As empresas com incentivos fiscais têm indicadores de estrutura maiores do que aquelas sem incentivos ficais. 
Formigoni, H., Segura, L. C., Teixeira, D. G. A., Carvalho, D. C., Marotti, M. G.; Relação entre incentivos fiscais e indicadores econômicos-financeiros de empresas abertas brasileiras.

\section{RESULTADO E ANÁLISE DE DADOS}

Por meio do site da B3 foi identificado, no ano de 2016, 28 (6\%) companhias abertas brasileiras não financeiras que usufruem de incentivos fiscais (grupo 1) e 422 (94\%) que não usufruem (grupo 2). Foram calculados os índices econômico-financeiros dos dois grupos de empresas e depois foi calculada a média de cada índice por grupo.

Entende-se que o percentual de empresas que usufruem de incentivos ficais não seja maior por conta da complexidade da legislação brasileira, que dificulta o acesso das empresas à obtenção de recursos governamentais.

A Tabela 1 apresenta o número de empresas que usufruíram de incentivos fiscais em 2016, por setor.

Tabela 1: Empresas com incentivos fiscais, por setor

\begin{tabular}{lc}
\hline Setor & $\mathbf{n}$ \\
\hline Água, esgoto e outros sistemas & 2 \\
Geração, transmissão e distribuição de energia elétrica & 4 \\
Indústria de calçados e outras & 5 \\
Outros setores & 17 \\
Total & $\mathbf{2 8}$ \\
\hline
\end{tabular}

Fonte: Elaborado pelos autores.

Conforme pode-se observar pela Tabela 1, os setores com mais empresas que usufruíram dos incentivos fiscais, dentre os 119 setores, são: indústria de calçados (18\%), geração, transmissão e distribuição de energia elétrica (14\%) e água, esgotos e outros sistemas (7\%).

Na sequência, para verificação da normalidade da distribuição amostral, foi utilizado o Teste de Kolmogorov Smirnov e o de Shapiro Wilk, apresentados na Tabela 2, que evidencia o resultado do teste para empresas com e sem incentivos fiscais. 
Formigoni, H., Segura, L. C., Teixeira, D. G. A., Carvalho, D. C., Marotti, M. G.; Relação entre incentivos fiscais e indicadores econômicos-financeiros de empresas abertas brasileiras.

Tabela 2 - Teste de normalidade da distribuição amostral.

\begin{tabular}{|c|c|c|c|c|c|c|c|}
\hline \multirow[b]{2}{*}{ Indicadores } & & \multicolumn{3}{|c|}{ Kolmogorov-Smirnov } & \multicolumn{3}{|c|}{ Shapiro-Wilk } \\
\hline & & Statistic & Df & Sig. & Statistic & df & Sig. \\
\hline \multirow[t]{2}{*}{ LiqSeca } & Sem Inc Fisc & 0,286 & 422 & 0,000 & 0,428 & 422 & 0,000 \\
\hline & Com Inc Fisc & 0,216 & 28 & 0,002 & 0,656 & 28 & 0,000 \\
\hline \multirow[t]{2}{*}{ LiqIme } & Sem Inc Fisc & 0,380 & 422 & 0,000 & 0,262 & 422 & 0,000 \\
\hline & Com Inc Fisc & 0,217 & 28 & 0,002 & 0,830 & 28 & 0,000 \\
\hline \multirow[t]{2}{*}{ LiqCor } & Sem Inc Fisc & 0,264 & 422 & 0,000 & 0,485 & 422 & 0,000 \\
\hline & Com Inc Fisc & 0,187 & 28 & 0,013 & 0,696 & 28 & 0,000 \\
\hline \multirow[t]{2}{*}{ LiqGer } & Sem Inc Fisc & 0,426 & 422 & 0,000 & 0,089 & 422 & 0,000 \\
\hline & Com Inc Fisc & 0,277 & 28 & 0,000 & 0,596 & 28 & 0,000 \\
\hline \multirow[t]{2}{*}{ ROE } & Sem Inc Fisc & 0,432 & 422 & 0,000 & 0,082 & 422 & 0,000 \\
\hline & Com Inc Fisc & 0,171 & 28 & 0,036 & 0,847 & 28 & 0,001 \\
\hline \multirow[t]{2}{*}{ ROI } & Sem Inc Fisc & 0,335 & 422 & 0,000 & 0,279 & 422 & 0,000 \\
\hline & Com Inc Fisc & 0,297 & 28 & 0,000 & 0,571 & 28 & 0,000 \\
\hline \multirow[t]{2}{*}{ ROA } & Sem Inc Fisc & 0,372 & 422 & 0,000 & 0,169 & 422 & 0,000 \\
\hline & Com Inc Fisc & 0,158 & 28 & 0,072 & 0,840 & 28 & 0,001 \\
\hline \multirow[t]{2}{*}{ MargEBIT } & Sem Inc Fisc & 0,494 & 422 & 0,000 & 0,049 & 422 & 0,000 \\
\hline & Com Inc Fisc & 0,343 & 28 & 0,000 & 0,613 & 28 & 0,000 \\
\hline \multirow[t]{2}{*}{ MargBruta } & Sem Inc Fisc & 0,243 & 422 & 0,000 & 0,558 & 422 & 0,000 \\
\hline & Com Inc Fisc & 0,131 & 28 & 0,200 & 0,975 & 28 & 0,712 \\
\hline \multirow[t]{2}{*}{ MargLíq } & Sem Inc Fisc & 0,483 & 422 & 0,000 & 0,042 & 422 & 0,000 \\
\hline & Com Inc Fisc & 0,300 & 28 & 0,000 & 0,703 & 28 & 0,000 \\
\hline \multirow[t]{2}{*}{ VarLucLiq } & Sem Inc Fisc & 0,384 & 422 & 0,000 & 0,218 & 422 & 0,000 \\
\hline & Com Inc Fisc & 0,513 & 28 & 0,000 & 0,217 & 28 & 0,000 \\
\hline \multirow[t]{2}{*}{ Endiv } & Sem Inc Fisc & 0,467 & 422 & 0,000 & 0,034 & 422 & 0,000 \\
\hline & Com Inc Fisc & 0,234 & 28 & 0,000 & 0,717 & 28 & 0,000 \\
\hline
\end{tabular}

Fonte: Elaborado pelos autores.

Pelo resultado apresentado na Tabela 2 verifica-se que a distribuição da amostra não é normal (Sig.<0,05).

Na Tabela 3 é apresentado o resultado do cálculo da média dos indicadores para cada grupo de empresas. 
Formigoni, H., Segura, L. C., Teixeira, D. G. A., Carvalho, D. C., Marotti, M. G.; Relação entre incentivos fiscais e indicadores econômicos-financeiros de empresas abertas brasileiras.

Tabela 3: Média dos indicadores para empresas com e sem incentivos fiscais

\begin{tabular}{llcccc}
\hline Indicadores & & $\mathbf{N}$ & Mean & Std. Deviation & Std. Error Mean \\
\hline LiqSeca & Sem Inc Fisc & 422 & 1,347 & 2,380 & 0,116 \\
& Com Inc Fisc & 28 & 1,630 & 1,461 & 0,276 \\
LiqIme & Sem Inc Fisc & 422 & 0,448 & 1,467 & 0,071 \\
& Com Inc Fisc & 28 & 0,338 & 0,343 & 0,065 \\
LiqCor & Sem Inc Fisc & 422 & 1,554 & 2,459 & 0,120 \\
& Com Inc Fisc & 28 & 2,045 & 1,632 & 0,308 \\
LiqGer & Sem Inc Fisc & 422 & 1,276 & 6,833 & 0,333 \\
& Com Inc Fisc & 28 & 1,439 & 1,594 & 0,301 \\
ROE & Sem Inc Fisc & 422 & $-0,071$ & 8,521 & 0,415 \\
& Com Inc Fisc & 28 & 0,189 & 0,177 & 0,033 \\
ROI & Sem Inc Fisc & 422 & 0,913 & 2,996 & 0,146 \\
& Com Inc Fisc & 28 & 1,086 & 1,602 & 0,303 \\
ROA & Sem Inc Fisc & 422 & $-0,062$ & 0,892 & 0,043 \\
& Com Inc Fisc & 28 & 0,066 & 0,099 & 0,019 \\
MargEBIT & Sem Inc Fisc & 422 & $-550,705$ & 8824,105 & 429,551 \\
& Com Inc Fisc & 28 & 13,396 & 39,067 & 7,383 \\
MargBruta & Sem Inc Fisc & 422 & 26,127 & 50,017 & 2,435 \\
& Com Inc Fisc & 28 & 40,159 & 21,231 & 4,012 \\
EargLíq & Sem Inc Fisc & 422 & $-3,295$ & 63,750 & 3,103 \\
& Com Inc Fisc & 28 & 0,110 & 0,290 & 0,055 \\
VarLucLiq & Sem Inc Fisc & 422 & 191466,32 & 1905197,35 & 92743,55 \\
& Com Inc Fisc & 28 & 2613944,79 & 13815960,39 & 13,085 \\
\hline \multirow{2}{*}{ Fondiv } & Sem Inc Fisc & 422 & 15,527 & 268,803 & 0,285 \\
\hline
\end{tabular}

Fonte: Elaborado pelos autores.

A Tabela 3 evidencia que os indicadores das empresas com incentivos fiscais são maiores do que os das empresas sem incentivos fiscais, exceto nos casos dos indicadores LiqIme e Endiv.

Tendo em vista que a amostra não apresentou distribuição normal, para verificar se as médias dos indicadores entre os diferentes grupos têm significância estatística, foi realizada a análise da diferença entre médias pelo teste não paramétrico U de Mann Whitney para amostras independentes, conforme apresentado na Tabela 4. 
Formigoni, H., Segura, L. C., Teixeira, D. G. A., Carvalho, D. C., Marotti, M. G.; Relação entre incentivos fiscais e indicadores econômicos-financeiros de empresas abertas brasileiras.

Tabela 4: Teste U de Mann- Whitney para os indicadores do estudo

\begin{tabular}{llll}
\hline & Hipótese nula & Sig & Decisão \\
\hline $\mathbf{1}$ & O indicador LiqSeca é similar nos dois grupos de empresas & 0,005 & Rejeita a hipótese nula \\
\hline $\mathbf{2}$ & O indicador LidIme é similar nos dois grupos de empresas & 0,050 & Aceita a hipótese nula \\
\hline $\mathbf{3}$ & O indicador LiqCor é similar nos dois grupos de empresas & 0,001 & Rejeita a hipótese nula \\
\hline $\mathbf{4}$ & O indicador LiqGer é similar nos dois grupos de empresas & 0,001 & Rejeita a hipótese nula \\
\hline $\mathbf{5}$ & O indicador ROE é similar nos dois grupos de empresas & 0,001 & Rejeita a hipótese nula \\
\hline $\mathbf{6}$ & O indicador ROI é similar nos dois grupos de empresas & 0,005 & Rejeita a hipótese nula \\
\hline $\mathbf{7}$ & O indicador ROA é similar nos dois grupos de empresas & 0,000 & Rejeita a hipótese nula \\
\hline $\mathbf{8}$ & O indicador MargEBIT é similar nos dois grupos de empresas & 0,030 & Rejeita a hipótese nula \\
\hline $\mathbf{9}$ & O indicador MargBruta é similar nos dois grupos de empresas & 0,007 & Rejeita a hipótese nula \\
\hline $\mathbf{1 0}$ & O indicador MargLíq é similar nos dois grupos de empresas & 0,000 & Rejeita a hipótese nula \\
\hline $\mathbf{1 1}$ & O indicador VarLucLiq é similar nos dois grupos de empresas & 0,030 & Rejeita a hipótese nula \\
\hline $\mathbf{1 2}$ & O indicador Endiv é similar nos dois grupos de empresas & 0,240 & Aceita a hipótese nula \\
\hline
\end{tabular}

Fonte: Elaborado pelos autores.

Pela Tabela 4, verifica-se que a média dos indicadores das empresas com incentivos fiscais, são estatisticamente diferentes daquelas sem incentivos fiscais (Sig.<0,05), exceto para os indicadores LiqIme e Endiv.

Com base nas Tabelas 3 e 4, verifica-se que as empresas que usufruem de incentivos fiscais apresentam:

1. melhores indicadores de liquidez (LiqSeca, LiqCor e LiqFer) do que aquelas que não usufruem. Assim, aceita-se a Hipótese 1 deste estudo de que as empresas com incentivo fiscal têm indicadores de liquidez maior do que aquelas sem incentivos fiscais. Dessa forma, pode-se inferir que empresas com incentivo fiscal têm maior capacidade de liquidez para cumprir suas obrigações com terceiros.

2. melhores indicadores de rentabilidade (ROE, ROI e ROA). Assim, aceita-se a Hipótese 2 deste estudo de que as empresas com incentivo fiscal têm indicadores de rentabilidade maior do que aquelas sem incentivos fiscais. Dessa forma, pode-se inferir que empresas com incentivo fiscal têm maior capacidade de obter retornos com a utilização dos recursos dos acionistas, dos investimentos e do ativo.

3. melhores indicadores de lucratividade (MargEBIT, MargBruta, MargLíq e VarLucLíq). Assim, aceita-se a Hipótese 3 deste estudo de que as empresas com incentivo fiscal têm indicadores de lucratividade maior do que aquelas sem incentivos fiscais. Dessa forma, pode-se inferir que empresas com incentivo fiscal 
Formigoni, H., Segura, L. C., Teixeira, D. G. A., Carvalho, D. C., Marotti, M. G.; Relação entre incentivos fiscais e indicadores econômicos-financeiros de empresas abertas brasileiras.

têm maior margem de ganho sobre o valor de venda dos seus produtos em relação àquelas que não possuem incentivos fiscais.

4. menores indicadores de estrutura (Endiv). Assim, rejeita-se a Hipótese 4 deste estudo de que as empresas com incentivo fiscal têm indicadores de estrutura maior do que aquelas sem incentivos fiscais. Dessa forma, pode-se inferir que empresas com incentivo fiscal têm um endividamento menor, comprometendo menos os recursos dos acionistas, tendo menor risco de crédito e maior possibilidade de alavancagem. 
Formigoni, H., Segura, L. C., Teixeira, D. G. A., Carvalho, D. C., Marotti, M. G.; Relação entre incentivos fiscais e indicadores econômicos-financeiros de empresas abertas brasileiras.

\section{CONSIDERAÇÕES FINAIS}

O presente trabalho visou analisar a relação entre incentivos fiscais e os indicadores econômico-financeiros de companhias abertas brasileiras não financeiras.

Por meio da B3 foram identificadas 28 empresas que usufruíram de incentivos fiscais no ano de 2016 e pelo banco de dados disponibilizado na Economática foram coletados os dados daquelas e de outras 422 empresas que não usufruíram dos incentivos fiscais.

Verificou-se que os incentivos fiscais e os indicadores econômico-financeiros das empresas da amostra apresentaram um relacionamento estatisticamente significativo, onde as empresas que usufruíram de incentivos ficais apresentaram uma situação econômico-financeira favorável.

Ao comparar os grupos de empresas formados por companhias abertas brasileiras não financeiras que usufruem dos incentivos fiscais versus aquelas que não usufruem, as primeiras apresentam indicadores econômico-financeiros (índices de: liquidez, rentabilidade, atividade e de endividamento) favoráveis.

Este fato impacta em maior capacidade de solver compromissos financeiros, maior rentabilidade na venda dos produtos, maiores margens de lucro na venda dos produtos e menor endividamento.

Alguns pontos que não foram explorados nesta pesquisa podem vir a sê-lo em pesquisas futuras, tal como a análise do impacto dos incentivos fiscais em setores empresariais específicos.

Cabe ressaltar aqui que os resultados desse trabalho se referem somente à amostra utilizada e, assim, não podem ser generalizados. 
Formigoni, H., Segura, L. C., Teixeira, D. G. A., Carvalho, D. C., Marotti, M. G.; Relação entre incentivos fiscais e indicadores econômicos-financeiros de empresas abertas brasileiras.

\section{REFERÊNCIAS BIBLIOGRÁFICAS}

ALVES, Renan Santos. O impacto da política fiscal sobre a atividade econômica ao longo do ciclo econômico: evidências para o Brasil. 2017. Dissertação (Mestrado em Teoria Econômica). Faculdade de Economia, Administração e Contabilidade, Universidade de São Paulo, São Paulo, 2017.

ALVES, B. A. M.; DUARTE, F. C. Aplicações a Extrafiscalidade no Direito Brasileiro. Direito e Desenvolvimento, João Pessoa, v. 7, n. 2, p. 280-300, 2017. ISSN 2236-0859. Disponível em:

〈https://periodicos.unipe.br/index.php/direitoedesenvolvimento/article/view/329/309>. Acesso em: 09 mai. 2018.

ASSAF NETO, A. Estrutura e análise de balanços: um enfoque econômico-financeiro. 9. ed. São Paulo: Atlas, 2010.

BRASIL. Senado Federal. Lei no 5.172 de 25 de outubro de 1966. Código Tributário Nacional e Legislação Correlata. Brasília, 1966. Disponível em:

<http://www2.senado.leg.br/bdsf/bitstream/handle/id/496301/000958177.pdf $>$. Acesso em: 29 ago. 2017.

. Lei $\mathbf{n}^{\circ}$ 6.404, de 15 de dezembro de 1976. Dispõe sobre as Sociedades por Ações. Diário Oficial da República Federativa do Brasil, Brasília, DF.

Lei Complementar $n^{0}$ 101, de 4 de maio de 2000. Lei de responsabilidade Fiscal. Estabelece normas de finanças públicas voltadas para a responsabilidade na gestão fiscal e dá outras providências. Diário Oficial da República Federativa do Brasil, Brasília, DF.

Ministério da Fazenda. Secretaria de Política Econômica. Relatório da

Distribuição Pessoal da Renda e da Riqueza da População Brasileira. Brasília, 2016.

Disponível em: <http://www.spe.fazenda.gov.br/noticias/distribuicao-pessoal-da-renda-e-dariqueza-da-populacao-brasileira/relatorio-distribuicao-da-renda-2016-05-09.pdf $>$. Acesso em: 09 mai. 2018.

. Ministério da Fazenda. Secretaria da Receita Federal do Brasil - SRFB. Carga

Tributária no Brasil - 2016: Análise por Tributo e Bases de Incidência. Brasília, 2017a. Disponível em: <http://idg.receita.fazenda.gov.br/dados/receitadata/estudos-e-tributarios-eaduaneiros/estudos-e-estatisticas/carga-tributaria-no-brasil/carga-tributaria-2016.pdf>. Acesso em: 09 mai. 2018.

. Ministério da Fazenda. Receita Federal do Brasil. Gastos Tributários - Previsões

PLOA. Disponível em http://idg.receita.fazenda.gov.br/dados/receitadata/renunciafiscal/previsoes-ploa/gastos-tributarios-2013-previsoes-ploa. Acesso em 08 jan 2019.

. Ministério da Integração Nacional. Incentivos Fiscais: Histórico. 2017b.

Disponível em: 〈http://www.mi.gov.br/historico3 >. Acesso em: 03 out. 2017. 
Formigoni, H., Segura, L. C., Teixeira, D. G. A., Carvalho, D. C., Marotti, M. G.; Relação entre incentivos fiscais e indicadores econômicos-financeiros de empresas abertas brasileiras.

BOVESPA. Índice BOVESPA e cotações grátis de todas as empresas da Bolsa. Toro Radar. 2017. Disponível em: <https://app.tororadar.com.br/bovespa/>. Acesso em: 30 out. 2017.

CALDERARO, F. R. S. Incentivos Fiscais à Exportação. Comentários à legislação específica na área tributária. São Paulo: Resenha Tributária, 1973.

CATELli, A. Controladoria: uma abordagem de gestão econômica. São Paulo: Atlas, 2001.

CHING, H. Y. Contabilidade gerencial: novas práticas para gestão dos negócios. São Paulo: Person Prentice Hall, 2006.

COMITÊ DE PRONUNCIAMENTOS CONTÁBEIS (CPC). Pronunciamento Técnico CPC 07 (R1) - Subvenção e Assistência Governamentais. 2010. Disponível em:

$<$ http://www.cpc.org.br/CPC/Documentos-

Emitidos/Pronunciamentos/Pronunciamento?Id=38>. Acesso em: 22 abr. 2018.

ECONOMÁTICA SYSTEM. Banco de dados Economática 2016-2017. Disponível em: <https://rdpviaweb-6-eco-web.economatica.com/ay/ecoCloud.html?lang=pt $>$. Acesso em: 31 out. 2017.

ELALI, A. Incentivos fiscais, neutralidade de tributação e desenvolvimento econômico: A questão da redução das desigualdades regionais e sociais. In: MARTINS, I. G. S. et al. (Coord.) Incentivos Fiscais: questões pontuais na esfera federal, estadual e municipal. São Paulo: MP, 2007. Disponível em:

<http://sisnet.aduaneiras.com.br/lex/doutrinas/arquivos/070807.pdf > . Acesso em: 04 nov. 2017.

FERREIRA, G. R.; CALLADO, A. C. Mensuração de Desempenho no Setor de Serviços: um estudo de caso em escritórios de contabilidade da cidade do Recife. Revista Conhecimento Contábil - UER/UFERSA, São Paulo: v. 5, n. 2, 5 nov. 2017. Disponível em: <http://www2.uern.br/index.php/ccontabil/article/view/2618>. Acesso em: 15 fev. 2018.

FORMIGONI, H. A influência dos incentivos fiscais sobre a estrutura de capital e a rentabilidade das companhias abertas brasileiras não financeiras. 2008. Tese (Doutorado em Controladoria e Contabilidade: Contabilidade). Faculdade de Economia, Administração e Contabilidade, Universidade de São Paulo, São Paulo, 2008.

FORMIGONI, H., POMPA ANTUNES, M., PAULO, E., PEREIRA, C. (2012). Estudo sobre os incentivos tributários para o gerenciamento de resultados contábeis nas companhias abertas brasileiras. Revista Base (Administração e Contabilidade) da UNISINOS, v. 9, n. 1, p. 4152. Disponível em: 〈http://www.redalyc.org/html/3372/337228649004/>. Acesso em: 22 out. 2017.

GADELHA, G. D. P. Isenção Tributária: Crise de Paradigma do Federalismo Fiscal. Curitiba: Juruá, 2010.

INSTITUTO BRASILEIRO DE PLANEJAMENTO TRIBUTÁRIO - IBPT. Carga Tributária/PIB x IDH - Cálculo do Índice de Retorno de Bem-Estar à Sociedade - IRBES. IBPT, 2018. Disponível em: 〈https://ibpt.com.br/〉. Acesso em: 08 jan. 2019. 
Formigoni, H., Segura, L. C., Teixeira, D. G. A., Carvalho, D. C., Marotti, M. G.; Relação entre incentivos fiscais e indicadores econômicos-financeiros de empresas abertas brasileiras.

KANNEBLEY JUNIOR, S.; PORTO, G. Incentivos fiscais à pesquisa, desenvolvimento e inovação no Brasil: uma avaliação das políticas recentes. Brasília, DF: Banco Intamericano de Desenvolvimento, 2012. Disponível em:

$<$ https://edisciplinas.usp.br/pluginfile.php/3512888/mod_resource/content/2/BID\%20incentiv os\%20fiscais\%20no\%20Brasil.pdf >. Acesso em: 20 out. 2017.

LOUREIRA, C. A.; SILVA, E. C; TATIANE, S. V. Manual de Direito Tributário: de acordo com a EC 75/2013 e com as mais recentes decisões do STJ e do STF. 6. ed. São Paulo: Saraiva, 2014.

MAZZILLI, Hugo Nigro. Regime jurídico do ministério público. São Paulo, Escola Superior do Ministério Público de S. Paulo - Curso para Analistas de Promotorias - 2012. Disponível em: <http://www.mazzilli.com.br/pages/informa/ESMP28112012.pdf>. Acesso em: 06 mai. 2018.

MELO, F. S. D. Incentivos fiscais e segurança jurídica. São Paulo: MP, 2007.

NASCIMENTO, S. P. Guerra fiscal: uma avaliação comparativa entre alguns estados participantes. Economia Aplicada, São Paulo, v. 12, n. 4, p. 677-706, dec. 2008. ISSN 19805330. Disponível em: 〈https://www.revistas.usp.br/ecoa/article/view/996/1008>. Acesso em: 13 mar. 2018.

NIYAMA, J. K; CAMPOS, E. S.; GONÇALVES, R. L.; CAMPOS, G. S. Reconhecimento, Mensuração e Evidenciação de Operações de Remunerações em Opções de Ações de Companhias Abertas Listadas nos Segmentos Especiais de Governança Corporativa pela BM\&FBOVESPA. Contabilidade Vista \& Revista, v. 23, n. 3, p. 49-72, 2012. Disponível em: <http://www.redalyc.org/html/1970/197026238003/>. Acesso em: 22 out. 2017.

OAB, Ordem de Advogados do Brasil. Principais diferenças entre as categorias e técnicas de desoneração do direito tributário. Disponível em: <http://www.oabsc.org.br/artigos/principais-diferencas-entre-as-categorias-e-tecnicas-desoneracao-do-direitotributario-nao-incidenci/362>. Acesso em: 06 mai. 2018.

PORTINHO, A. R. Incentivos de Natureza Setorial e incentivos à atividade de Exportação. In: Âmbito Jurídico, Rio Grande, v. III, n. 11, nov. 2002. Disponível em:

<http://www.ambitojuridico.com.br/site/index.php?n_link=revista_artigos_leitura\&artigo_id=4845> > Acesso em: 04 nov. 2017.

PUREZA, M. E. M. Disciplinamento das renúncias de receitas federais inconsistências no controle dos gastos tributários. Câmara dos Deputados. Estudos e Notas técnicas. 2007. Disponível em: <http://www2.camara.leg.br/orcamento-dauniao/estudos/2007/Estudo052007.pdf>. Acesso em: 15 ago. 2017.

RAMEIRO, M. C.; COÊLHO, K. C. Análise Econômico Financeira. Perito Contador, 2011. Disponível em: <http://peritocontador.com.br/wp-content/uploads/2015/03/Maria-Carolina-eKellen-Cuimar-Co\%C3\%AAlho-An\%C3\%A1lise-Econ\%C3\%B4mico-Financeira.pdf>. Acesso em: 13 out 2017. 
Formigoni, H., Segura, L. C., Teixeira, D. G. A., Carvalho, D. C., Marotti, M. G.; Relação entre incentivos fiscais e indicadores econômicos-financeiros de empresas abertas brasileiras.

RECEITA FEDERAL DO BRASIL - RFB - Evolução da carga tributária no Brasil 2006 a 2015. Disponível em: <http://idg.receita.fazenda.gov.br/dados/receitadata/estudos-etributarios-e-aduaneiros/estudos-e-estatisticas/carga-tributaria-no-brasil/ctb-2015.pdf $>$. Acesso em: 30.out.2017.

RIBEIRO, M. G. Município e incentivos fiscais. Dissertação (Mestrado em Direito Político e Econômico). Faculdade de Direito da Universidade Presbiteriana Mackenzie, São Paulo, 2009. 173f. Disponível em:

<http://up.mackenzie.br/fileadmin/user_upload/_imported/fileadmin/PUBLIC/UP_MACKEN ZIE/servicos_educacionais/stricto_sensu/Direito_Politico_Economico/Marcelo_Gollo_Ribeir o.pdf>. Acesso em: 15 out. 2017.

RODRIGUES, L., RODRIGUES, E. Governo abre mão de R\$ 283 bilhões em incentivos fiscais no Orçamento de 2018. Jornal O Estado de São Paulo - Estadão. Economia e Negócios online. Disponível em: <http://economia.estadao.com.br/noticias/geral,governoabre-mao-de-r-283-bi-em-incentivos-fiscais-no-orcamento-de-2018,70001998065>. Acesso em: 13 out. 2017.

SAMPIERI, H. R.; COLLADO, C. H.; LUCIO, P. B. Metodologia de pesquisa. 3. ed. São Paulo: McGraw-Hill, 2006.

SILVIA, J. P. D. Análise financeira das empresas. 7. ed. São Paulo: Atlas, 2005.

SOARES, M. A. Análise de indicadores para avaliação de desempenho econômicofinanceiro de operadoras de planos de saúde brasileiras: uma aplicação da análise fatorial. 2006. Dissertação (Mestrado em Controladoria e Contabilidade: Contabilidade). Faculdade de Economia, Administração e Contabilidade da Universidade de São Paulo, São Paulo, 2006. Disponível em: 〈http://10.11606/D.12.2006.tde-15122006-121519>. Acesso em: 15 fev. 2018.

STEAGALL, M.; LOO, T. V. D.; BRITO, A. Cartilha sobre uso de incentivos fiscais. FECOMERCIO, 2015. Disponível em: <http://www.fecomercio.com.br/upload/_v1/2015-0730/13544.pdf >. Acesso em: 10 out. 2017.

TCU, Tribunal de Contas da União. Carga Tributária Nacional e Carga Tributária Comparada na versão simplificada do Relatório e Parecer Prévio sobre as Contas do Governo da República. Tribunal de Contas da União. Disponível em:

<http://portal.tcu.gov.br/tcu/paginas/contas_governo/contas_2009/Textos/Ficha\%203\%20\%20Carga\%20Tributaria.pdf >. Acesso em: 13 ago. 2017.

WEF - World Economic Forum. The Global Competitiveness Report 2016-2017. World Economic Forum Reports 2016. Disponível em: 〈https://doi.org/92-95044-35-5>. Acesso em: 09 mar. 2018.

WEF - World Economic Forum. The Global Competitiveness Report 2018. World Economic Forum Reports 2018. Disponível em:

<http://www3.weforum.org/docs/GCR2018/05FullReport/TheGlobalCompetitivenessReport2 018.pdf>. Acesso em: 08 jan. 2019. 